\title{
Comprehensive analysis of allergen-specific IgE in COPD: mite-specific lgE specifically related to the diagnosis of asthma-COPD overlap
}

Hikaru Toyota, Naoya Sugimoto, Konomi Kobayashi, Yuki Suzuki, Yuri Takeshita, Ayaka Ito, Mariko Ujino, Fuminori Tomyo, Hirokazu Sakasegawa, Yuta Koizumi, Michio Kuramochi, Masao Yamaguchi and Hiroyuki Nagase*

\begin{abstract}
Background: Although the relationship between allergic sensitization and increased respiratory symptoms of chronic obstructive pulmonary disease (COPD) has been suggested, which allergen has a significant effect on COPD pathology is unclear. This study aimed to identify the specific lgE related to clinical features of COPD and the diagnosis of asthma-COPD overlap (ACO).

Methods: We recruited 76 patients with COPD and analyzed $39 \mathrm{lgE}$ using panel lgE test (View Allergy $39^{\circledR}$ ). ACO was diagnosed according to the Japanese Respiratory Society Guidelines.

Results: As for perennial aeroallergens, the positivity for moth (31.5\%), Candida (23.7\%), Dermatophagoides pteronyssinus (22.4\%) and house dust (22.4\%), and concerning pollen, Japanese cedar (35.5\%) and Japanese cypress (22.2\%) exceeded 20\%. Only the positivity of IgE for Dermatophagoides pteronyssinus and house dust was significantly higher in ACO compared with that in non-ACO COPD. Moreover, it contributed to the diagnosis of ACO in an IgE class-dependent manner. Patients with cockroach IgE exhibited higher residual volume, whereas those with Japanese cedar lgE exhibited better diffusion capacity than negative patients. The contribution for ACO diagnosis by the receiver operating characteristic curve analysis was comparable among total IgE (cutoff value: $158 \mathrm{IU} / \mathrm{mL}$ ), blood eosinophil count (234/ $\mu \mathrm{L})$, and fraction of exhaled nitric oxide (31.0 ppb).
\end{abstract}

Conclusions: The prominent role of mite-specific $\lg E$ in the diagnosis and pathology of ACO and the potentially detrimental effect of cockroach sensitization on air trapping in COPD were suggested. The finding highlights the future development of a treatment targeting lgE as a treatable trait in COPD.

Keywords: ACO, Cockroach, Dermatophagoides pteronyssinus, Eosinophils, Fraction of exhaled nitric oxide, View allergy 39

*Correspondence: nagaseh@med.teikyo-u.ac.jp

Division of Respiratory Medicine and Allergology, Department of Medicine, Teikyo University School of Medicine, 2-11-1, Kaga, Itabashi-ku, Tokyo 173-8605, Japan

\begin{abstract}
Background
Allergic sensitization is an established feature of asthma, and assessment of sensitization status is recommended for patients with asthma [1]. In contrast, allergic sensitization may not be routinely assessed in patients with chronic obstructive pulmonary disease (COPD),
\end{abstract}


and the diagnosis of allergy is not recommended by the Global Initiative for Chronic Obstructive Lung Disease (GOLD) [2]. However, allergic sensitization has been reported to be related to increased respiratory symptoms and risk of exacerbations in patients with COPD [3] and may be a potential treatable trait by avoidance of allergen or by anti-immunoglobulin E (IgE) treatment [4]. Although the positivity of 5 [3] or 6 [5] allergen-specific IgE in patients with COPD was analyzed, the number of tested allergens was limited, and the relationship between allergen-specific IgE and patient characteristics was not fully elucidated.

The concept of asthma-COPD overlap (ACO) has been introduced in recent years, and various diagnostic criteria have been proposed [6]. Allergic sensitization leads to type 2 inflammation, which is a prominent feature of asthma and may serve as an important component of $\mathrm{ACO}$ diagnosis. However, the diagnostic criteria of ACO did not always include IgE categories [7]. Although some recent guidelines introduced elevated levels of IgE into the diagnostic criteria $[8,9]$, the cutoff level of IgE was not stated in the guidelines, including the Japanese Respiratory Society (JRS) published in $2018[10,11]$. Some studies compared the levels of total and several allergen-specific IgE between ACO and pure COPD and revealed that the levels of total IgE [5] or Dermatophagoides-specific IgE $[5,6]$ were higher in ACO. However, the number of tested allergens was limited, and which allergen-specific IgE is optimal for ACO diagnosis remains unclear. Concerning JRS guideline, although the prevalence of ACO was reported to be $30.4 \%$ among patients with fixed airflow limitation [10], the positivity of specific IgE in ACO was not independently exhibited [10]. In addition, although recent evidence suggests the interactions between food allergy and asthma [12], the relationship between food allergy and ACO or COPD is largely unknown.

This study aimed to comprehensively analyze the panel of specific IgE among patients with COPD and to investigate the relationship between each specific $\operatorname{IgE}$ and clinical features, including pulmonary function, or ACO diagnosis. To do this, we adopted panel IgE test that can simultaneously measure 39 specific IgE. In addition, we compared the contribution of IgE with the fraction of exhaled nitric oxide (FeNO) or blood eosinophils with ACO diagnosis and attempted to elucidate the relative importance of IgE.

\section{Methods}

\section{Study design and patient population}

This was a cross-sectional study that investigated COPD patients in the outpatient clinic of Teikyo University Hospital. COPD was diagnosed according to the GOLD criteria [2]. Medical information and laboratory findings were retrospectively obtained from medical records and estimated under stable conditions before completing the survey for ACO. Specific IgE levels were measured using panel IgE test (View Allergy $39^{\circledR}$, Thermo Fisher Diagnostics K.K., Tokyo, Japan) and judged as positive when the class was equal to or greater than 1 . NIOX VERO $^{\circledR}$ (Aerocrine, Morrisville, NC, USA) was used to measure FeNO. The panel IgE test includes specific IgE for pollens or molds, which are shown to be highly prevalent in Japan [13].

\section{Definition of ACO}

ACO was diagnosed according to the JRS Guidelines for the Management of ACO 2018 [11]. In brief, ACO was defined as having fixed airflow limitation (forced expiratory volume in $1 \mathrm{~s}\left[\mathrm{FEV}_{1}\right] /$ forced vital capacity $[\mathrm{FVC}]<70 \%$ ) with 1 or more of the COPD features plus 2 or more of the asthma features (Additional File 1). Variable or paroxysmal symptoms suggesting asthma were analyzed by self-completed questionnaire. The diagnosis of perennial rhinitis was made by selfcompleted SACRA questionnaire based on the Allergic Rhinitis and Its Impact on Asthma guidelines [14]. The criterion for elevated IgE was judged as positive when the level of serum total IgE exceeded $100 \mathrm{IU} / \mathrm{mL}$ based on the institutional standard value or when the class of specific IgE was equal to or greater than class 1 . Although we analyzed 85 COPD patients (Additional File 2), a portion of the patients could not be judged to have ACO or not because all tests indicated in Additional File 1 could not be performed. As such, these patients were excluded from the analysis concerning ACO. Among evaluable 76 patients, $44.7 \%$ of the patients were diagnosed with ACO.

\section{Statistical analysis}

Bartlett's test was employed to check the variances across samples. Differences between the two groups were analyzed using Student's t-test or Mann-Whitney U-test when the variances were equal or different, respectively. The relationship between biomarkers was analyzed by Spearman's correlation coefficient. The receiver operating characteristic (ROC) analysis was employed to find a cutoff value for biomarkers to detect ACO diagnosis. Multivariate logistic regression analysis was employed to estimate odds ratios (ORs) with 95\% confidence intervals (CIs) for ACO diagnosis. Statistical significance was defined as $P<0.05$, and data were presented as mean \pm standard error of the mean. JMP ${ }^{\circledR} 14$ (SAS Institute Japan, Tokyo, Japan) or Prism ${ }^{\circledR} 8$ (GraphPad Software, San Diego, CA, USA) was used for statistical analyses. 


\section{Results}

We analyzed the positivity of 39 allergen-specific IgE in all COPD patients. Concerning the perennial aeroallergens, the positivity for moth (31.5\%), Candida (23.7\%), Dermatophagoides pteronyssinus (D. pteronyssinus, $22.4 \%)$, and house dust (22.4\%) was $>20 \%$ (Fig. 1). As for pollen allergens, the positivity for Japanese cedar (35.5\%) and Japanese cypress (22.2\%) exceeded $20 \%$. As for foods or other allergens, the positivity for shrimp/lobster (15.5\%), bananas (15.5\%), and wheat (12.7\%) was higher than $10 \%$.

We also compared the characteristics of patients who are positive with those who are negative for specific IgE (Fig. 2; Additional File 3). In patients with positive IgE for cockroach, residual volume (RV) was significantly higher (136.7\% vs $110.2 \%)$, and $\mathrm{FEV}_{1}$ tended to be lower
(69.5\% vs $78.7 \%)$ compared with patients with negative IgE (Fig. 2). Contrarily, in patients with positive IgE for Japanese cedar, the diffusion capacity of carbon monoxide/alveolar volume $\left(\mathrm{DL}_{\mathrm{CO}} / \mathrm{V}_{\mathrm{A}}\right)$ was significantly higher than in patients with negative IgE (92.1\% vs $73.2 \%)$ (Fig. 2). The prevalence of perennial allergic rhinitis was significantly higher in patients with positive specific IgE for all allergens, except for Japanese cedar, which causes seasonal rhinitis only in the spring season (Additional File 3).

Furthermore, we compared patient characteristics between ACO and non-ACO COPD (Table 1). In ACO, body mass index and FeNO were significantly higher compared with non-ACO COPD. FEV 1 , \%predicted also tended to be lower in ACO, and FeNO was significantly higher in patients with values that fell in the lower half

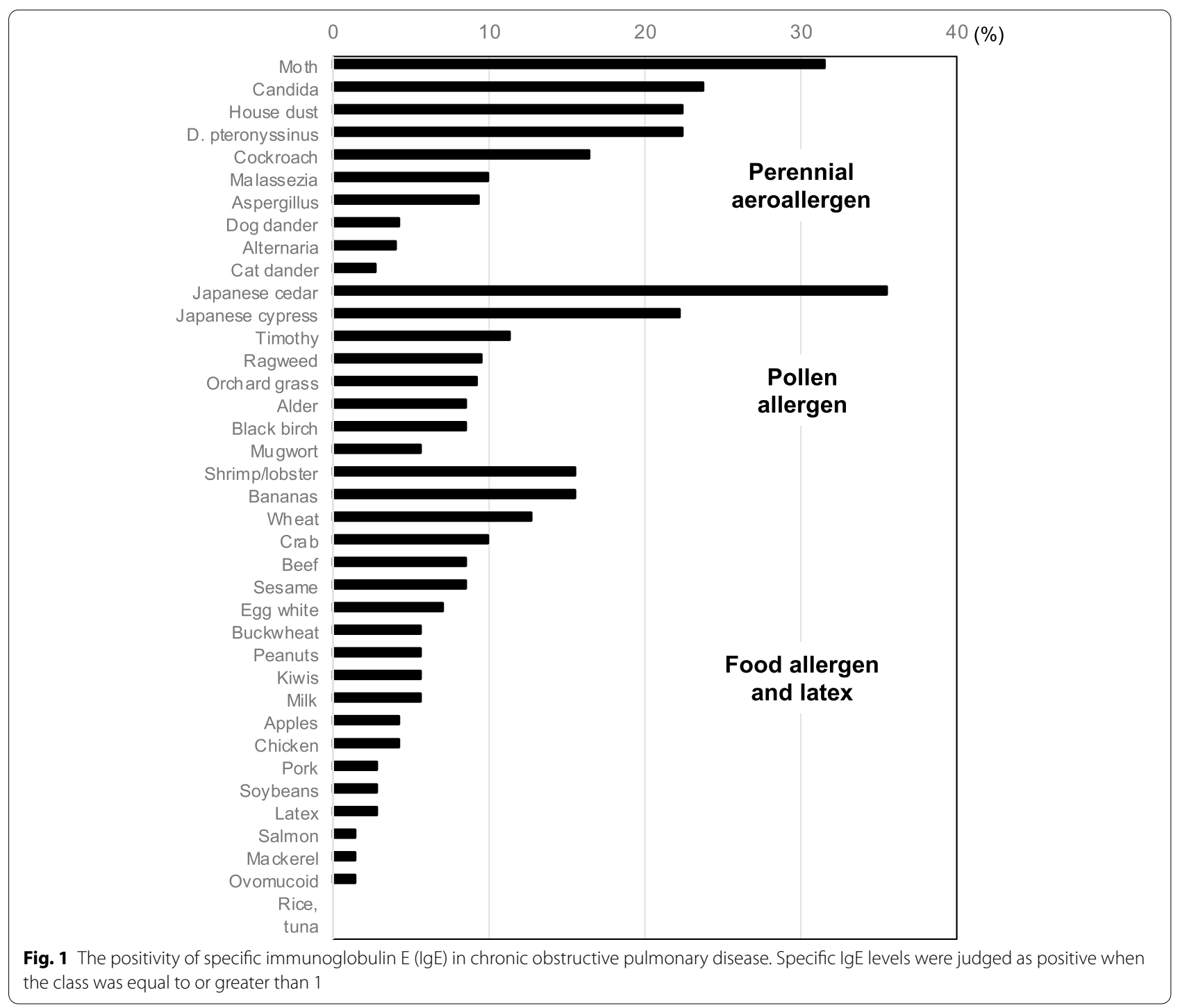




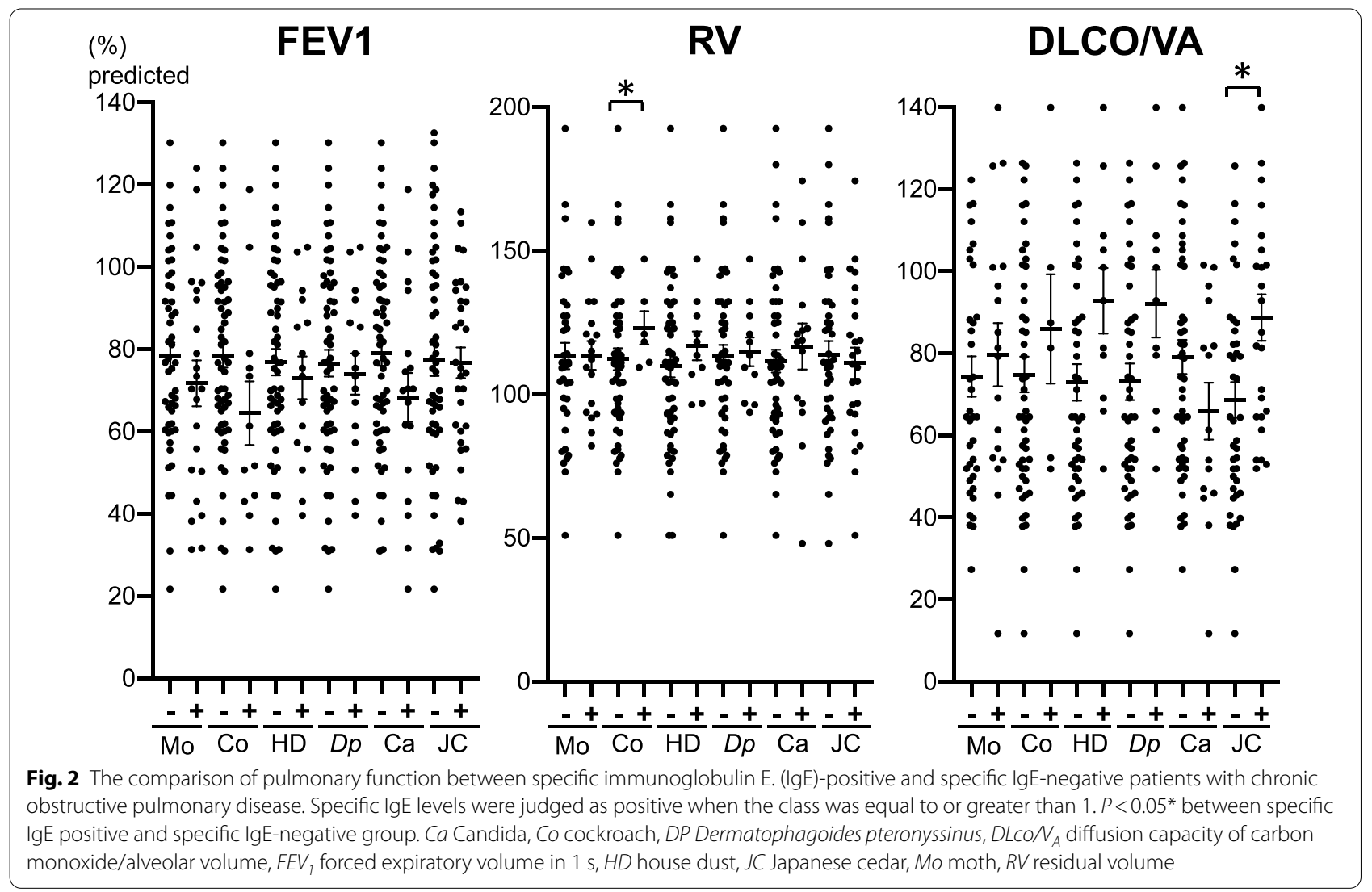

of $\mathrm{FEV}_{1}$, \%predicted (26.3 vs $40.8 \mathrm{ppb}, P<0.05$ ). A significantly greater proportion of patients with ACO exhibited all the features of asthma, except for airway reversibility (Additional File 4).

Next, we compared the positivity of specific IgE between ACO and non-ACO COPD (Table 2). Among various aeroallergens, only the positivity for house dust and D. pteronyssinus was significantly higher in ACO. As for other perennial aeroallergens, the positivity for moth, Candida, and Malassezia was numerically higher in ACO without statistical significance. As for pollen, the positivity for Japanese cedar tended to be higher in ACO $(P=0.16)$. Concerning food allergens, the overall positivity for beef-specific IgE was low (8.5\%); however, the positivity was significantly lower in ACO. We also analyzed the relationship between the value of IgE class and the proportion of patients diagnosed with ACO (Fig. 3). Only house dust- and D. pteronyssinus-specific IgE showed significant relationship between the class of specific IgE and ACO diagnosis.

As the diagnostic criteria for ACO included FeNO and blood eosinophil count, in addition to IgE levels, we compared the utility of those biomarkers in ACO diagnosis by the ROC curve analysis. Although there were weak or no significant relationships between those biomarkers (Additional File 5), the area under the curve for ACO diagnosis was comparable among three biomarkers: 0.666 (95\% CI $0.540-0.793, P=0.013$ ) for blood eosinophil count, 0.665 (95\% CI 0.538-0.791, $P=0.014$ ) for total IgE, and 0.703 (95\% CI 0.578-0.829, $P=0.0027$ ) for FeNO (Fig. 4). There were no significant differences between the ROC curves for ACO diagnosis (IgE vs blood eosinophil count: $P=0.99$, IgE vs FeNO $P=0.67$, FeNO vs blood eosinophil count: $P=0.64$ ). The best cutoff value for diagnosis was 234 count $/ \mu \mathrm{L}$ for blood eosinophils, $158 \mathrm{IU} / \mathrm{mL}$ for serum total IgE, and $31.0 \mathrm{ppb}$ for FeNO.

The contribution of blood eosinophils, FeNO, and IgE was analyzed to further determine the relative importance of the different biomarkers in ACO diagnosis. In univariate analysis, the criteria, except for blood eosinophils, significantly contributed to ACO diagnosis (FeNO: OR 9.58, 95\% CI 2.45-37.4, $P<0.01$, IgE: OR 3.93, 95\% CI 1.45-10.68, $P<0.01)$. In addition, although specific IgE for house dust $(P=0.0146)$ and $D$. pteronyssinus $(P=0.0146)$ significantly contributed to the diagnosis of ACO, positivity for moth $(P=0.2564)$, cockroach $(P=0.5653)$, Japanese cedar pollen $(P=0.1593)$, and Candida $(P=0.2917)$ did not exhibit significant contributions. We also analyzed the 
Table 1 Comparison of patient characteristics between ACO and non-ACO COPD patients

\begin{tabular}{|c|c|c|c|c|}
\hline & ACO & Non-ACO COPD & Total & $P$ value \\
\hline Subject (n) & 34 & 42 & 76 & \\
\hline Sex male (\%) & 82.4 & 81.0 & 81.6 & 0.88 \\
\hline Body mass index $\left(\mathrm{kg} / \mathrm{m}^{2}\right)$ & $24.1 \pm 0.6$ & $22.3 \pm 0.6$ & $23.1 \pm 3.8$ & $0.042^{*}$ \\
\hline Age (years) & $72.5 \pm 1.3$ & $74.3 \pm 1.2$ & $73.5 \pm 7.6$ & 0.30 \\
\hline Smoking status (current/ex/never [\%]) & 20.6/79.4/0 & $7.1 / 90.5 / 2.4$ & $13.2 / 85.5 / 1.3$ & 0.16 \\
\hline Smoking history (pack-years) & $55.7 \pm 5.8$ & $62.0 \pm 5.2$ & $59.2 \pm 34.0$ & 0.43 \\
\hline FVC, \%predicted & $107.6 \pm 3.1$ & $105.4 \pm 2.8$ & $106.4 \pm 17.8$ & 0.59 \\
\hline $\mathrm{FEV}_{1}(\mathrm{~L})$ & $1.68 \pm 0.12$ & $1.82 \pm 0.10$ & $1.76 \pm 0.68$ & 0.39 \\
\hline $\mathrm{FEV}_{1}, \%$ predicted & $72.9 \pm 4.1$ & $79.6 \pm 3.7$ & $76.6 \pm 24.2$ & 0.24 \\
\hline $\mathrm{FEV}_{1} / \mathrm{FVC}$ ratio $(\%)$ & $51.5 \pm 2.4$ & $57.1 \pm 2.2$ & $54.6 \pm 14.1$ & 0.088 \\
\hline RV, \% predicted ${ }^{a}$ & $111.2 \pm 5.1$ & $112.8 \pm 5.0$ & $112.0 \pm 27.2$ & 0.82 \\
\hline DLco $N_{A}, \%$ predicted $^{b}$ & $80.7 \pm 5.7$ & $72.6 \pm 5.6$ & $76.6 \pm 30.9$ & 0.32 \\
\hline Airway reversibility $(\mathrm{mL})^{c}$ & $131.0 \pm 23.1$ & $102.9 \pm 21.6$ & $116.0 \pm 105.6$ & 0.38 \\
\hline Airway reversibility $(\%)^{c}$ & $9.3 \pm 1.8$ & $5.8 \pm 1.7$ & $7.4 \pm 8.4$ & 0.16 \\
\hline Blood eosinophil count (cells/ $\mu \mathrm{L}$ ) & $248 \pm 29$ & $218 \pm 26$ & $231 \pm 167$ & 0.45 \\
\hline Serum total lgE (IU/mL) & $375 \pm 84$ & $258 \pm 75$ & $310 \pm 488$ & 0.31 \\
\hline FeNO (ppb) ${ }^{d}$ & $33.8 \pm 2.6$ & $20.7 \pm 2.3$ & $26.4 \pm 16.1$ & $<0.01^{* *}$ \\
\hline ICS use before diagnosis of ACO (\%) & 35.3 & 7.1 & 19.7 & $<0.01^{* *}$ \\
\hline LABA (\%) & 85.3 & 73.8 & 79.0 & 0.22 \\
\hline LAMA (\%) & 82.4 & 81.0 & 81.6 & 0.88 \\
\hline Theophylline (\%) & 20.6 & 14.3 & 17.1 & 0.47 \\
\hline LTRA (\%) & 17.7 & 2.4 & 9.2 & $0.022^{*}$ \\
\hline Antihistamine (\%) & 14.7 & 7.1 & 10.5 & 0.29 \\
\hline \multicolumn{5}{|c|}{$\begin{array}{l}A C O \text { asthma-COPD overlap, } C O P D \text { chronic obstructive pulmonary disease, } D L C O / V_{A} \text { diffusing capacity of carbon monoxide/alveolar volume, FeNO fraction of exhaled } \\
\text { nitric oxide, } F E V_{1} \text { forced expiratory volume in } 1 \mathrm{~s}, F V C \text { forced vital capacity, ICS inhaled corticosteroid, IgE immunoglobulin } E, L A B A \text { long-acting } \beta \text {-agonists, } L A M A \text { long- } \\
\text { acting muscarinic receptor antagonist, } R V \text { residual volume, } L T R A \text { leukotriene receptor antagonist }\end{array}$} \\
\hline \multicolumn{5}{|l|}{ a $\mathrm{RV}$} \\
\hline \multicolumn{5}{|l|}{ b $D L C O / V_{A}(A C O n=29$, non-ACO COPD $n=30)$} \\
\hline \multicolumn{5}{|c|}{ c Airway reversibility $(\mathrm{ACO} n=21$, non-ACO COPD $n=24)$} \\
\hline \multicolumn{5}{|c|}{${ }^{d}$ FeNO $($ ACO $n=33$, non-ACO COPD $n=42)$} \\
\hline \multicolumn{5}{|c|}{$P<0.05^{*}, P<0.01^{* *}$ between $\mathrm{ACO}$ and non-ACO COPD groups } \\
\hline
\end{tabular}

contribution of the number of sensitized allergens, and the number did not contribute to the diagnosis of ACO $(P=0.98)$.

Concerning IgE factors, all of the following criteria significantly contributed to ACO diagnosis: total IgE $>100 \mathrm{IU} / \mathrm{mL}$, positive for house dust-specific IgE, and positive for $D$. pteronyssinus-specific IgE. In the three models for multivariate analyses (Table 3), all IgE criteria significantly contributed to ACO diagnosis, in addition to FeNO $>35$ ppb criterion.

\section{Discussion}

For the first time, we comprehensively analyzed a panel of 39 specific IgE in patients with COPD and revealed the importance of $D$. pteronyssinus - and house dustspecific IgE for the diagnosis or pathology of ACO by the following observations. First, the positivity of $D$. pteronyssinus and house dust was significantly higher in
ACO group than in the non-ACO COPD group (Table 2). Second, the frequency of ACO diagnosis was increased in IgE class-dependent manner of those allergens (Fig. 3). Lastly, multivariate analysis revealed the significant contribution of total IgE and house dust- and $D$. pteronyssinus-specific IgE to ACO diagnosis (Table 3). As mites have been identified as a major antigenic substance in house dust [15], those results suggested the specifically important role of sensitization to mite allergen in the pathology or diagnosis of ACO. In addition, as the patients with cockroach-specific IgE exhibited higher RV and patients with Japanese cedar-specific IgE exhibited better $\mathrm{DL}_{\mathrm{CO}} / \mathrm{V}_{\mathrm{A}}$ compared with negative patients (Fig. 2), the allergen-specific effect on COPD pathology was also suggested.

A previous report using skin prick test or ImmunoCAP, wherein results were highly correlated with the current panel IgE test [16], revealed that the positivity of $D$. 
Table 2 Comparison of positivity in specific IgE between ACO and non-ACO COPD

\begin{tabular}{|c|c|c|c|c|c|c|c|c|c|}
\hline & ACO & $\begin{array}{l}\text { Non-ACO } \\
\text { COPD }\end{array}$ & Total & $P$ value & & ACO & $\begin{array}{l}\text { Non-ACO } \\
\text { COPD }\end{array}$ & Total & $P$ value \\
\hline \multicolumn{5}{|c|}{ Perennial aeroallergen } & \multicolumn{5}{|c|}{ Food allergen and latex } \\
\hline Moth & 38.7 & 26.2 & 31.5 & 0.26 & Shrimp/lobster & 16.7 & 14.6 & 15.5 & 0.82 \\
\hline Candida & 29.4 & 19.1 & 23.7 & 0.29 & Bananas & 20.0 & 12.2 & 15.5 & 0.37 \\
\hline House dust & 35.3 & 11.9 & 22.4 & $0.015^{* *}$ & Wheat & 13.3 & 12.2 & 12.7 & 0.89 \\
\hline D. pteronyssinus & 35.3 & 11.9 & 22.4 & $0.015^{* *}$ & Crab & 3.3 & 14.6 & 9.9 & 0.11 \\
\hline Cockroach & 19.4 & 14.3 & 16.4 & 0.56 & Beef & 0.0 & 14.6 & 8.5 & $0.029^{*}$ \\
\hline Malassezia & 13.3 & 7.3 & 9.9 & 0.40 & Sesame & 3.3 & 12.2 & 8.5 & 0.18 \\
\hline Aspergillus & 12.1 & 7.1 & 9.3 & 0.46 & Buckwheat & 3.3 & 7.3 & 5.6 & 0.47 \\
\hline Dog dander & 3.3 & 4.8 & 4.2 & 0.76 & Apples & 0.0 & 7.3 & 4.2 & 0.13 \\
\hline Alternaria & 6.1 & 2.4 & 4.0 & 0.42 & Chicken & 0.0 & 7.3 & 4.2 & 0.13 \\
\hline Cat dander & 6.1 & 0.0 & 2.7 & 0.11 & Egg white & 6.7 & 7.3 & 7.0 & 0.92 \\
\hline \multicolumn{5}{|l|}{ Pollen allergen } & Peanuts & 3.3 & 7.3 & 5.6 & 0.47 \\
\hline Japanese cedar & 44.1 & 28.6 & 35.5 & 0.16 & Kiwis & 6.7 & 4.9 & 5.6 & 0.75 \\
\hline Japanese cypress & 19.4 & 24.4 & 22.2 & 0.61 & Milk & 3.3 & 7.3 & 5.6 & 0.47 \\
\hline Orchard grass & 14.7 & 9.5 & 11.8 & 0.49 & Pork & 0.0 & 4.9 & 2.8 & 0.22 \\
\hline Timothy & 13.3 & 9.8 & 11.3 & 0.64 & Soybeans & 0.0 & 4.9 & 2.8 & 0.22 \\
\hline Ragweed & 11.8 & 7.1 & 9.2 & 0.49 & Latex & 0.0 & 4.9 & 2.8 & 0.22 \\
\hline Alder & 3.3 & 12.2 & 8.5 & 0.18 & Salmon & 0.0 & 2.4 & 1.4 & 0.39 \\
\hline Black birch & 3.3 & 12.2 & 8.5 & 0.18 & Mackerel & 0.0 & 2.4 & 1.4 & 0.39 \\
\hline \multirow[t]{2}{*}{ Mugwort } & 3.3 & 7.3 & 5.6 & 0.47 & Ovomucoid & 3.3 & 0.0 & 1.4 & 0.24 \\
\hline & & & & & Rice, tuna & 0.0 & 0.0 & 0.0 & - \\
\hline
\end{tabular}

$\mathrm{n}=76, P<0.05^{*}, P<0.01^{* *}$ between ACO and non-ACO COPD groups. Specific IgE was judged as positive when the class was equal to or greater than 1 $A C O$ asthma-COPD overlap, COPD chronic obstructive pulmonary disease, $D$. pteronyssinus Dermatophagoides pteronyssinus

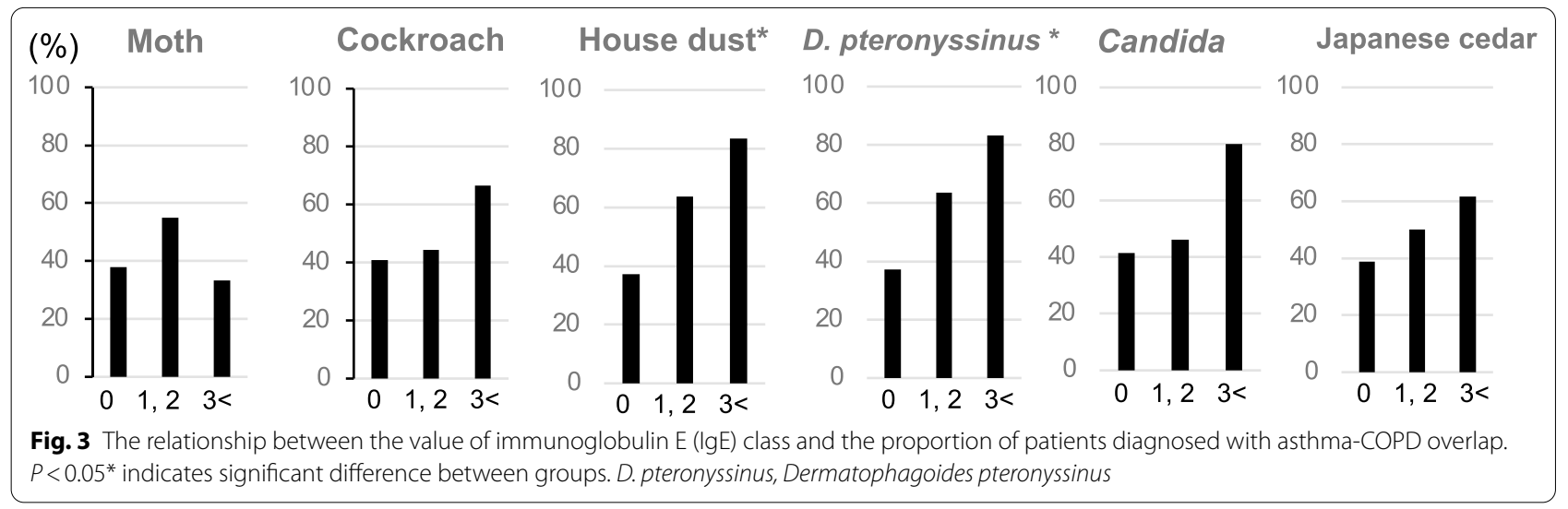

pteronyssinus-and house dust-specific IgE in patients with asthma was higher compared with patients with COPD [17, 18]. Contrarily, the positivity for Candida (23.7\%) and moth (31.5\%) in this study was comparable to the reported positivity in asthma [17] and was not significantly different between $\mathrm{ACO}$ and non-ACO COPD (Table 2). Those results suggested the specifically important role of sensitization to mites in the diagnosis of ACO from COPD.
The positivity for cockroach-specific IgE in COPD has been reported to be comparable to the positivity in asthma, but higher than in the control group [13, 18, 19]. In addition, no significant difference in positivity of cockroach-specific IgE was observed between ACO and non-ACO COPD in this study (Table 1). Taken together, sensitization to cockroach seems to have little role in distinguishing asthma and COPD or diagnosing ACO. Interestingly, RV was significantly higher, and the $\mathrm{FEV}_{1}$ 


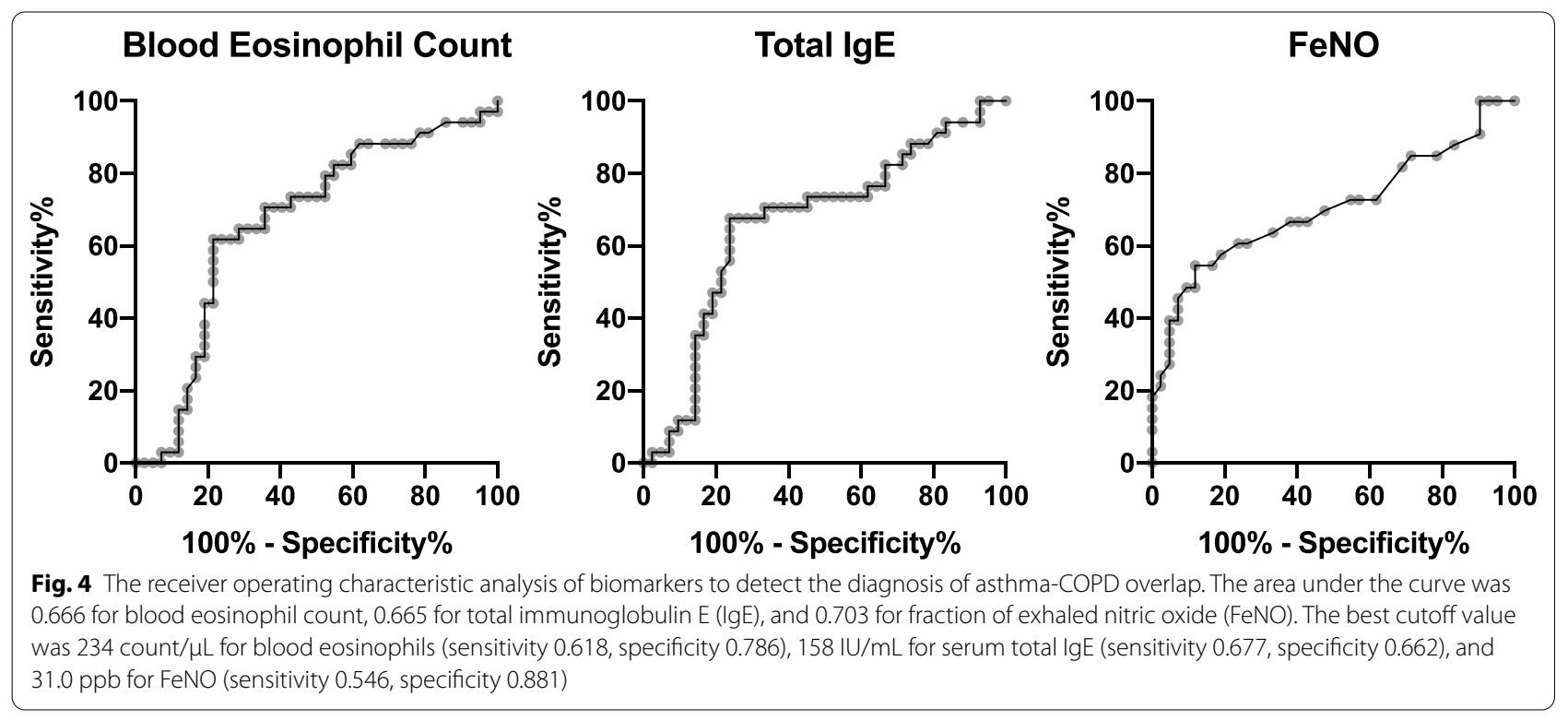

Table 3 Multivariate analysis of biomarkers
for the diagnosis of ACO

\begin{tabular}{lrrrc}
\hline & OR & Cl & & P value \\
\hline Model 1 & & & & \\
Blood eosinophils $>300 \mu \mathrm{L}$ & 1.25 & 0.39 & 4.02 & 0.71 \\
FeNO $>35 \mathrm{ppb}$ & 15.34 & 3.03 & 77.57 & $<0.01^{* *}$ \\
IgE $>100 \mathrm{IU} / \mathrm{mL}$ & 6.18 & 1.74 & 21.88 & $<0.01^{* *}$ \\
Model 2 & & & & \\
Blood eosinophils $>300 \mu \mathrm{L}$ & 2.12 & 0.69 & 6.45 & 0.19 \\
FeNO $>35 \mathrm{ppb}$ & 7.98 & 1.95 & 32.74 & $<0.01^{* *}$ \\
House dust lgE positive & 3.74 & 1.04 & 13.46 & $0.038^{*}$ \\
Model 3 & & & & \\
Blood eosinophils $>300 \mu \mathrm{L}$ & 2.12 & 0.70 & 6.45 & 0.19 \\
FeNO > 35 ppb & 7.98 & 1.95 & 32.74 & $<0.01^{* *}$ \\
D. pteronyssinus IgE positive & 3.74 & 1.04 & 13.46 & $0.038^{*}$ \\
\hline
\end{tabular}

Specific IgE was judged as positive when the class was equal to or greater than 1. The sensitivity, specificity, positive predictive value, and negative predictive value for diagnosis of ACO are as follows: Blood eosinophils $>300 \mu \mathrm{L}(44.1 \%$, $76.2 \%, 60.0 \%, 62.7 \%)$, FeNO > 35 ppb (42.4\%, 92.9\%, 82.4\%, 67.2\%), IgE > 100 IU/ $\mathrm{mL}(70.6 \%, 61.9 \%, 60.0 \%, 72.2 \%)$, House dust IgE positive $(35.3 \%, 88.1 \%, 70.6 \%$, $62.7 \%)$, D. pteronyssinus IgE positive (35.3\%, 88.1\%, 70.6\%, 62.7\%)

$\mathrm{Cl}$ confidence interval, D. pteronyssinus Dermatophagoides pteronyssinus, FeNO fraction of exhaled nitric oxide, IgE immunoglobulin $\mathrm{E}, \mathrm{OR}$ odds ratios

tended to be lower in cockroach IgE positive COPD (Fig. 2). The high level of exposure to cockroach was reported to increase the risk of asthma development [20] and its severity [21]. Cockroach extract was shown to induce secretions of various cytokines and chemokines from airway epithelial cells [22, 23]. In addition, allergen component of cockroach, Per a 10 is a serine protease, which induces the generation of IL-6, IL-8, and GM-CSF from epithelial cells through the activation of proteaseactivated receptor 2 [24, 25]. These proinflammatory natures of cockroach allergen might cause a detrimental effect on the airway structure of COPD, and detection of cockroach-specific IgE might help identify air trapping in COPD.

The reason why $\mathrm{DL}_{\mathrm{CO}} / \mathrm{V}_{\mathrm{A}}$ was significantly higher in Japanese cedar-sensitized patients (Fig. 2) remains unclear. Japanese cedar pollen is the most common seasonal allergen in Japan and causes seasonal allergic rhinitis during the spring season. Concomitant pollinosis was not related to chronic asthma severity, although asthma exacerbations increased during the cedar pollen season [26]. As cedar pollens have a diameter of more than $30 \mu \mathrm{m}$, they mainly deposit in the upper airways and might not have a detrimental effect on gas exchange.

Recognizing treatable traits in chronic airway diseases has been emphasized [4], and the definition of ACO was not referred in the latest GOLD document [2]. Nevertheless, the cluster analysis based on transcription factor characterizing the subset of helper $\mathrm{T}$ cells identified the ACO phenotype with elevated IgE and blood eosinophils, suggesting the existence of ACO endotypes [27]. In addition, detecting specific IgE in COPD is still important, because IgE-mediated inflammation is potentially a treatable trait. The importance of sensitized allergen avoidance has been stressed [4], and the effect of anti-IgE antibody, omalizumab, is expected in ACO. A small retrospective analysis of omalizumab revealed the improvement in the symptoms of patients with severe asthma who have smoking history and fixed airway obstruction [28]. However, studies on ACO are limited 
$[29,30]$, and another exploratory study of omalizumab in patients with COPD with elevated IgE level was terminated due to difficulty in recruiting eligible patients (NCT00851370). In our analysis, patients diagnosed with ACO tended to show lower $\mathrm{FEV}_{1}$ compared with non-ACO COPD, and patients with cockroach-specific IgE exhibited higher RV than nonsensitized patients. In this context, the efficacy of anti-IgE treatment for ACO diagnosed from clinical COPD or COPD sensitized with cockroach should be established in the future study.

This study has some limitations. The importance of IgE for ACO diagnosis may vary depending on the diagnostic criteria. There are various diagnostic criteria for ACO including $[8,11]$ or not including $\operatorname{IgE}[5,7$, 9]. When we applied the consensus definition by Sin et al. [9] to our study population, the proportion of patients with $\mathrm{IgE}>100 \mathrm{IU} / \mathrm{mL}$ or positive $\mathrm{IgE}$ for $D$. pteronyssinus tended to be higher in ACO than in nonACO COPD $(68.8 \%$ vs $48.0 \%[P=0.148]$ and $37.5 \%$ vs $20.0 \%[P=0.155]$, respectively). Although the use of ICS may affect the diagnosis of ACO, only three patients were treated by ICS in non-ACO COPD; therefore, the effect on the overall results was limited. Due to the nature of multiple testing, analyzing more patients is desirable for future analysis especially concerning the role of specific IgE for pollens and cockroach. In addition to our current findings, the general importance of mite-specific IgE in the diagnosis or pathology of ACO was suggested. Although geographical variation in the positivity of specific IgE may exist, sensitization to $D$. pteronyssinus was most prevalent among various developed countries [31] and different areas in Japan [13]. It remains unclear whether ACO diagnosed from clinical asthma and clinical COPD has identical pathophysiology. Our findings concerning the utility of IgE for diagnosing ACO is limited to ACO diagnosed from COPD.

\section{Conclusions}

In conclusion, by analyzing a panel of specific IgE in COPD, we revealed the specifically important role of mite-specific IgE in the diagnosis or pathology of ACO and the potentially detrimental effect of cockroach sensitization to air trapping in COPD. The finding highlights future study for developing a novel treatment strategy targeting IgE as a treatable trait in patients with ACO.

\section{Supplementary Information}

The online version contains supplementary material available at https://doi. org/10.1186/s13223-021-00514-9.
Additional file 1 Features of COPD or asthma described by the Japanese Respiratory Society Guideline

Additional file $\mathbf{2}$ The number of patients analyzed in the study

Additional file $\mathbf{3}$ Comparison of patient characteristics based on positivity for allergen specific lgE

Additional file $\mathbf{4}$ Proportion of patients fulfilling the criteria for features of asthma

Additional file $\mathbf{5}$ Relationships between blood eosinophil count, total lgE level, and FeNO

\section{Abbreviations}

ACO: Asthma-COPD overlap; Cl: Confidence intervals; COPD: Chronic obstructive pulmonary disease; $\mathrm{DL}_{\mathrm{CO}} \mathrm{N}_{\mathrm{A}}$ : Diffusing capacity of carbon monoxide/alveolar volume; D. pteronyssinus: Dermatophagoides pteronyssinus; FeNO: Fraction of exhaled nitric oxide; FEV 1 : Forced expiratory volume in $1 \mathrm{~s}$; FVC: Forced vital capacity; GOLD: Global initiative for chronic obstructive lung disease; IgE: Immunoglobulin E; JRS: Japanese Respiratory Society; OR: Odds ratio; ROC: Receiver operating characteristic; RV: Residual volume; SEM: Standard error of the mean.

\section{Acknowledgements}

The authors are grateful to Ms. Asako Tsukamoto and Ms. Eriko Endo for their outstanding secretarial assistance and effort in processing the data. The author would like to thank Enago (www.enago.jp) for the English language review.

\section{Authors' contributions}

$\mathrm{HT}$ and $\mathrm{HN}$ designed the study, collected the patient data, interpreted the results, and wrote manuscripts. NS, KK, YS, Al, YT, MU, FT, HS, YK, KM, and MY collected the patient data. All authors read and approved the final version of the manuscript.

\section{Funding}

This study was not funded.

\section{Availability of data and materials}

The datasets used and/or analysed during the current study are available from the corresponding author (nagaseh@med.teikyo-u.ac.jp) on reasonable request under permission from Ethical Review Board.

\section{Ethics approval and consent to participate}

This study was approved by Teikyo University Ethical Review Board for Medical and Health Research Involving Human Subjects (19-179). Written informed consent was obtained from all subjects.

Consent for publication

Not applicable.

\section{Competing interests}

The authors report no competing interest.

Received: 2 August 2020 Accepted: 11 January 2021

Published online: 04 February 2021

\section{References}

1. Ichinose M, Sugiura H, Nagase H, Yamaguchi M, Inoue H, Sagara H, et al. Japanese guidelines for adult asthma 2017. Allergol Int. 2017;66(2):163-89.

2. Global Strategy for the Diagnosis, Management, and Prevention of Chronic Obstructive Pulmonary Disease. 2020 REPORT. (https://goldcopd. org/wp-content/uploads/2019/11/GOLD-2020-REPORT-ver1.0wms.pdf). Accessed 26 Apr 2020. 
3. Jamieson DB, Matsui EC, Belli A, McCormack MC, Peng E, Pierre-Louis $S$, et al. Effects of allergic phenotype on respiratory symptoms and exacerbations in patients with chronic obstructive pulmonary disease. Am J Respir Crit Care Med. 2013;188(2):187-92.

4. Sterk PJ. Chronic diseases like asthma and COPD: do they truly exist? Eur Respir J. 2016;47(2):359-61.

5. Hersh CP, Zacharia S, PrakashArivuChelvan R, Hayden LP, Mirtar A, Zarei S, et al. Immunoglobulin $\mathrm{E}$ as a biomarker for the overlap of atopic asthma and chronic obstructive pulmonary disease. Chronic Obstr Pulm Dis. 2020;7(1):1-12.

6. Yanagisawa S, Ichinose M. Definition and diagnosis of asthma-COPD overlap (ACO). Allergol Int. 2018;67(2):172-8.

7. Diagnosis of Diseases of Chronic Airflow Limitation: Asthma COPD and Asthma-COPD Overlap Syndrome (ACOS). Based on the Global Strategy for Asthma Management and Prevention and the Global Strategy for the Diagnosis, Management and Prevention of Chronic Obstructive Pulmonary Disease. 2015. (https://goldcopd.org/wp-content/uploa ds/2016/04/GOLD_ACOS_2015.pdf). Accessed 26 Apr 2020.

8. Soler-Cataluña JJ, Cosío B, Izquierdo JL, López-Campos JL, Marín JM, Agüero R, et al. Consensus document on the overlap phenotype COPD asthma in COPD. Archivos de Bronconeumología (English Edition). 2012:48(9):331-7.

9. Sin DD, Miravitlles M, Mannino DM, Soriano JB, Price D, Celli BR, et al. What is asthma-COPD overlap syndrome? Towards a consensus definition from a round table discussion. Eur Respir J. 2016;48(3):664-73.

10. Yamamura K, Hara J, Kobayashi T, Ohkura N, Abo M, Akasaki K, et al. The prevalence and clinical features of asthma-COPD overlap (ACO) definitively diagnosed according to the Japanese Respiratory Society Guidelines for the Management of ACO 2018. J Med Invest. 2019;66:157.

11. Kyogoku Y, Sugiura H, Ichikawa T, Numakura T, Koarai A, Yamada M, et al. Nitrosative stress in patients with asthma-chronic obstructive pulmonary disease overlap. J Allergy Clin Immunol. 2019;144(4):972-83e14.

12. Emons JAM, Gerth van Wijk R. Food allergy and asthma: is there a link? Curr Treat Options Allergy. 2018;5(4):436-44.

13. Minami $T$, Fukutomi $Y$, Inada $R$, Tsuda $M$, Sekiya $K$, Miyazaki $M$, et al. Regional differences in the prevalence of sensitization to environmental allergens: analysis on lgE antibody testing conducted at major clinical testing laboratories throughout Japan from 2002 to 2011 . Allergol Intern. 2019;68(4):440-9.

14. Ohta K, Bousquet PJ, Aizawa H, Akiyama K, Adachi M, Ichinose M, et al. Prevalence and impact of rhinitis in asthma. SACRA, a cross-sectional nation-wide study in Japan. Allergy. 2011;66(10):1287-95.

15. Miyamoto T, Oshima S, Ishizaki T, Sato SH. Allergenic identity between the common floor mite (Dermatophagoides farinae Hughes, 1961) and house dust as a causative antigen in bronchial asthma. J Allergy. 1968:42(1):14-28.

16. Yamana Y, Fukuda K, Ko R, Uchio E. Local allergic conjunctivitis: a phenotype of allergic conjunctivitis. Int Ophthalmol. 2019;39(11):2539-44.

17. Adachi M, Ohta K, Morikawa A, Nishima S. Asthma insights \& reality in Japan 2005. Arerugi. 2006;55(10):1340-3 (in Japanese).
18. Bozek A, Rogala B. IgE-dependent sensitization in patients with COPD. Ann Agric Environ Med. 2018;25(3):417-20.

19. Kaji DA, Belli AJ, McCormack MC, Matsui EC, Williams DL, Paulin L, et al. Indoor pollutant exposure is associated with heightened respiratory symptoms in atopic compared to non-atopic individuals with COPD. BMC Pulm Med. 2014;14:147.

20. Litonjua AA, Carey VJ, Burge HA, Weiss ST, Gold DR. Exposure to cockroach allergen in the home is associated with incident doctordiagnosed asthma and recurrent wheezing. J Allergy Clin Immunol. 2001;107(1):41-7.

21. Do DC, Zhao Y, Gao P. Cockroach allergen exposure and risk of asthma. Allergy. 2016;71(4):463-74.

22. Page K, Hughes VS, Odoms KK, Dunsmore KE, Hershenson MB. German cockroach proteases regulate interleukin-8 expression via nuclear factor for interleukin-6 in human bronchial epithelial cells. Am J Respir Cell Mol Biol. 2005;32(3):225-31.

23. Pomes A, Mueller GA, Randall TA, Chapman MD, Arruda LK. New insights into cockroach allergens. Curr Allergy Asthma Rep. 2017;17(4):25.

24. Hong JH, Lee SI, Kim KE, Yong TS, Seo JT, Sohn MH, et al. German cockroach extract activates protease-activated receptor 2 in human airway epithelial cells. J Allergy Clin Immunol. 2004;113(2):315-9.

25. Kale SL, Arora N. Per a 10 activates human derived epithelial cell line in a protease dependent manner via PAR-2. Immunobiology. 2015;220(4):525-32.

26. Hojo M, Ohta K, likura M, Hirashima J, Sugiyama H, Takahashi K. The impact of co-existing seasonal allergic rhinitis caused by Japanese Cedar Pollinosis (SAR-JCP) upon asthma control status. Allergol Int. 2015;64(2):150-5.

27. Hirai K, Shirai T, Suzuki M, Akamatsu T, Suzuki T, Hayashi I, et al. A clustering approach to identify and characterize the asthma and chronic obstructive pulmonary disease overlap phenotype. Clin Exp Allergy. 2017;47(11):1374-82.

28. Maltby S, Gibson PG, Powell H, McDonald VM. Omalizumab treatment response in a population with severe allergic asthma and overlapping COPD. Chest. 2017;151(1):78-89.

29. Tat TS, Cilli A. Omalizumab treatment in asthma-COPD overlap syndrome. J Asthma Off J Assoc Care Asthma. 2016;53(10):1048-50.

30. Yalcin AD, Celik B, Yalcin AN. Omalizumab (anti-lgE) therapy in the asthma-COPD overlap syndrome (ACOS) and its effects on circulating cytokine levels. Immunopharmacol Immunotoxicol. 2016;38(3):253-6.

31. Bousquet PJ, Chinn S, Janson C, Kogevinas M, Burney P, Jarvis D. Geographical variation in the prevalence of positive skin tests to environmental aeroallergens in the European Community Respiratory Health Survey I. Allergy. 2007;62(3):301-9.

\section{Publisher's Note}

Springer Nature remains neutral with regard to jurisdictional claims in published maps and institutional affiliations.

Ready to submit your research? Choose BMC and benefit from:

- fast, convenient online submission

- thorough peer review by experienced researchers in your field

- rapid publication on acceptance

- support for research data, including large and complex data types

- gold Open Access which fosters wider collaboration and increased citations

- maximum visibility for your research: over $100 \mathrm{M}$ website views per year

At BMC, research is always in progress.

Learn more biomedcentral.com/submissions 